\title{
Femtosecond laser ablation and nanoparticle formation in intermetallic NiAl
}

\author{
David J. Jorgensen ${ }^{1}$ \\ Materials Department, Engineering II, Rm 1355, University of California, Santa Barbara, CA 93106-5050, USA \\ Michael S. Titus \\ Materials Department, Engineering II, Rm 1355, University of California, Santa Barbara, CA 93106-5050, USA \\ Tresa M. Pollock \\ Materials Department, Engineering II, Rm 1355, University of California, Santa Barbara, CA 93106-5050, USA
}

\begin{abstract}
The ablation behavior of a stoichiometric intermetallic compound $\beta$-NiAl subjected to femtosecond laser pulsing in air has been investigated. The single-pulse ablation threshold for NiAl was determined to be $83 \pm 4 \mathrm{~mJ} / \mathrm{cm}^{2}$ and the transition to the high-fluence ablation regime occurred at $2.8 \pm 0.3 \mathrm{~J} / \mathrm{cm}^{2}$. Two sizes of nanoparticles consisting of $\mathrm{Al}, \mathrm{NiAl}, \mathrm{Ni}_{3} \mathrm{Al}$ and $\mathrm{NiO}$ were formed and ejected from the target during high-fluence ablation. Chemical analysis revealed that smaller nanoparticles $(1-30 \mathrm{~nm})$ tended to be rich in $\mathrm{Al}$ while larger nanoparticles $(>100 \mathrm{~nm})$ were lean in Al. Ablation in the low-fluence regime maintained this trend. Redeposited material and nanoparticles remaining on the surface after a single $3.7 \mathrm{~J} / \mathrm{cm}^{2}$ pulse, one hundred $1.7 \mathrm{~J} / \mathrm{cm}^{2}$ pulses, or one thousand $250 \mathrm{~mJ} / \mathrm{cm}^{2}$ pulses were enriched in $\mathrm{Al}$ relative to the bulk target composition. Further, the surface of the irradiated high-fluence region was depleted in $\mathrm{Al}$ indicating that the fs laser ablation removal rate of the intermetallic constituents in this regime does not scale with the individual pure element ablation thresholds.

keywords: femtosecond laser ablation; intermetallic alloy; nickel aluminum; NiAl; nanoparticles; rapid solidification segregation
\end{abstract}

\section{Introduction}

Femtosecond laser ablation is useful for many applications such as the creation of nanoparticles [1], thin film deposition [2], micromachining [3-5], 3D tomography [6], microfluidics [4, 7], and

\footnotetext{
${ }^{1}$ davidjjorgensen@engr.ucsb.edu, fax:(805) 893-8486
} 
measuring the properties of thin films on substrates [8]. Paramount to all of these techniques is a detailed understanding of the fluence-ablation relationship of the materials systems. While the scientific literature contains a plethora of ablation characterization studies for simple systems such as pure metals [9-15], polymers [16, 17], glasses [18, 19], and semiconductors $[9,20-22]$ and for complex systems such as superalloys $[23,24]$ and biomaterials $[25,26]$, there is a relative dearth of information regarding systems of intermediate complexity such as intermetallics and simple compounds $[1,21,27]$. For this reason an in-depth study of the ablation behavior of the intermetallic $\beta$-phase NiAl is presented. This material is of industrial importance as a model high-temperature coating system that forms a thermally grown $\alpha-\mathrm{Al}_{2} \mathrm{O}_{3}$ oxide.

$\mathrm{NiAl}$ has a $\mathrm{B} 2$ crystal structure (ordered $\mathrm{BCC}, \mathrm{CsCl}$ prototype) meaning that all $\mathrm{Al}$ and $\mathrm{Ni}$ atoms are bonded to their nearest neighbors by eight identical bonds. The ablation threshold of the pure constituent metals is $105-135 \mathrm{~mJ} / \mathrm{cm}^{2}$ for $\mathrm{Al}[9,28]$ and $40-42 \mathrm{~mJ} / \mathrm{cm}^{2}$ for $\mathrm{Ni}[9,11]$. The present study demonstrates that the ablation behavior of the intermetallic NiAl is fundamentally different from either of its metallic constituents. Furthermore, the formation of nanoparticles in the ablation process in both the low-fluence and high-fluence ablation regimes has been studied.

\section{Experiment}

The fs laser ablation experiments were carried out in ambient air $\left(22.8^{\circ} \mathrm{C}, 49-72 \%\right.$ humidity $)$ with a Clark MXR CPA Series pulsed Ti:Sapphire laser with a $1 \mathrm{kHz}$ repetition rate, $780 \mathrm{~nm}$ wavelength, and $150 \mathrm{fs}$ pulse width. The variability in the laser output power was below $1 \%$ within the time frame of the experiment. The beam was attenuated with a combination of neutral density filters and a rotating half-wave plate followed by a p-polarized beam splitter before being focused by a $500 \mathrm{~mm}$ focal length plano-convex lens to a $54.4 \mu \mathrm{m} 1 / e^{2}$ radius.

A series of single pulse and 100-pulse experiments were conducted with the laser orthogonally incident onto the target, which was stoichiometric NiAl polished to a mirror finish $(0.25 \mu \mathrm{m}$ diamond suspension). The range of laser power used was between 0.92 and $590 \mathrm{~mW}$, corresponding to average fluences ranging from $0.010-6.4 \mathrm{~J} / \mathrm{cm}^{2}$.

After the laser experiments were conducted, the samples were ultrasonically cleaned in deionized water and methanol for two minutes before profile measurements and microscopy. The depth of the ablation craters was measured with a Veeco white light optical interferometer (WYKO NT1100). 
The single-pulse experiments were measured using the phase-shifting interferometry (PSI) mode wherein the optical path length is altered and a lateral shift in the fringe pattern is used to create interferograms to determine the surface height profile. This measurement mode has sub-nanometer vertical resolution. The 100-pulse craters, which were approximately one hundred times deeper than the single-pulse craters and too rough for continuous fringe patterns required in PSI, were measured with the vertical scanning interferometry (VSI) mode. This mode scans the measurement head vertically and determines the height at which pixels are in maximum focus with approximately nanometer vertical resolution.

The surface profiles of the craters were post-processed to remove optical aberrations created by the measuring system and then a $10 \times 10$ pixel box surrounding the lowest point in the crater was used to determine the maximum depth, $d_{0}$, for the experiment. The uncertainty in the depth was taken as the standard deviation of the 100 values within the box. In a few cases with high fluences, the depth was determined manually due to a large amount of missing data confounding the automatic fitting routines.

Initial surface chemical analyses were performed with an FEI Versa 3D microscope with a $30 \mathrm{~mm}$ EDAX Octane silicon drift detector. Further analysis of the nanoparticles ejected during ablation was performed with an FEI T20 TEM equipped with an EDAX Si(Li) Energy Dispersive X-ray Spectroscopy (EDS) detector and an FEI XL30 equipped with an EDAX Apollo X EDS detector. No attempt was made to quantify the amount of oxygen or carbon in the samples with EDS due unreliable measurements with light elements. To collect a sufficient quantity of nanoparticles for analysis, a series of twenty-five identical 100-pulse high-fluence regime or 1000-pulse low-fluence regime experiments were performed consecutively. A carbon support TEM grid (Formvar) was cut into a Pac-Man shape and held 1-3 mm away from the target approximately parallel to the surface. The laser beam passed through the "mouth" of the grid and irradiated the NiAl sample. Particles ablated from the target and impacted the grid to be analyzed by SEM and TEM. The crystal structures were analyzed using selected area diffraction patterns (SADPs) for various agglomerated particles. A gold standard was used to calibrate the TEM camera length. Powder diffraction simulations were carried out using JEMS for various metals, intermetallics, and oxides in order to determine the crystal structures. 


\section{Results}

\subsection{Ablation depth dependence on laser fluence}

Figure 1 shows the experimental results from both the single-pulse and the 100-pulse series of tests as the maximum ablation depth, $d_{0}$, per pulse as a function of average laser fluence, $\phi_{\text {avg }}$, along with best fits as explained in Section 4. For the 100-pulse experiments, the ablation depth reported is the average depth per pulse. The diameter of the laser beam at focus is over 100 $\mu \mathrm{m}$, so it is not expected that there are any steep edges affecting absorption or confining the ablated plume/particles because the aspect ratio of the crater is low (maximum depth in 100-pulse experiments is $10.5 \mu \mathrm{m})$.

\subsection{Chemical analysis of the low-fluence ablation regime}

As previously documented, the ablation behavior of many materials differs between the lowfluence and the high-fluence ablation regimes [10]. For metallic materials in the low-fluence regime, the ablated material is a liquid-like layer that is ejected from the surface without the formation of plasma [13, 29, 30] and leaves behind no appearance of surface melting. Laser-induced periodic surface structures (LIPSS) are formed with their orientation depending on the laser polarization after multiple pulses due to interactions with surface plasmons [30]. An example of LIPSS in NiAl is shown in Figure 3.

Energy dispersive X-ray spectroscopy (EDS) analysis of the center of the ablation crater produced after one thousand pulses with $\phi_{\mathrm{avg}}=250 \mathrm{~mJ} / \mathrm{cm}^{2}$ (upper inset of Figure 3) shows no significant deviation from the target composition, which was measured via EDS to be $50.3 \pm 0.1$ at\% Al. However, analysis of the redeposition layer at the perimeter of the crater (bright contrast in the lower inset of Figure 3) shows 58.3 at\% Al.

In addition, a high magnification EDS map was collected from the center of a low-fluence, one hundred-pulse crater made with a fluence similar to that in Figure 3. The signal from the peaks and valleys of the surface undulations (LIPSS) was segmented using the gray value from the associated electron image. The integrated composition of the peaks was measured to be 2 at\% enriched in $\mathrm{Al}$ while the valleys were 2 at\% depleted in $\mathrm{Al}$ compared to the average composition of the crater, which was the same as the bulk polished surface. Precise quantification of the chemical fluctuation is not possible with EDS due to the large interaction volume of the EDS signal in comparison 
with the size of the LIPSS. This measurement is noteworthy, although prone to error due to the geometry of the surface as explained in Section 4.3.

Analysis of the TEM grid that collected material ablated from twenty-five, one thousand-pulse low-fluence ablation events (see red diamond in Figure 1) shows a thick film consisting of Ni, Al, and $\mathrm{O}$ atoms. At the edge of the film it was possible to distinguish clusters of smaller nanoparticles $(1-30 \mathrm{~nm})$ that will henceforth be referred to as "nanoclusters" and larger nanoparticles that were (100-200 nm). An SEM EDS point-scan analysis of four nanocluster groupings (such shown by the orange triangles in Figure 5) indicated a $54 \pm 4$ at\% Al composition whereas five measurements of the nanoparticles gave $46 \pm 8$ at\% $\mathrm{Al}$ (such shown by the blue squares in Figure 5). TEM analysis produced similar results. The film in bulk was found to be stoichiometric.

\subsection{Chemical analysis of the high-fluence ablation regime}

The high-fluence ablation regime is characterized by a melting appearance in the target and the detection of a laser induced breakdown spectroscopy (LIBS) signal [13, 29, 30], indicating the formation of plasma from the target. The target surface no longer forms LIPSS after multiple pulses, but rather has the appearance of a melted and re-solidified layer.

EDS spot scans were performed on a collection of nanoparticles remaining at the bottom of a single-pulse crater with $\phi_{\text {avg }}=3.7 \mathrm{~J} / \mathrm{cm}^{2}$ (see Figure $4 \mathrm{a}$ ) and a 100-pulse crater with $\phi_{\text {avg }}=$ $1.7 \mathrm{~J} / \mathrm{cm}^{2}$ (see Figure $4 \mathrm{~b}$ ) following high-fluence ablation experiments. The nanoclusters remaining in both craters are rich in $\mathrm{Al}$ compared to the target composition. The X-ray signal interaction depth is estimated to be approximately $0.5 \mu \mathrm{m}$ by Monte Carlo simulations [31], meaning that the EDS measurements are sampling some of the surface below the nanoclusters. For this reason, the composition of the nanoclusters is likely to be more enriched in Al than measured. In addition, Figure $4 \mathrm{~b}$ shows the surface of the high-fluence irradiated area covered in nanoclusters, which interfere with measurements of the irradiated surface due to an enhanced signal caused by their spherical shape. For this reason, twelve spot scans were taken from both the particles and the irradiated surface of the crater in Figure $4 \mathrm{~b}$ to acquire a statistical representation of the chemistry. The chemical composition of the nanoparticles on the surface was $51.4 \pm 0.2$ at\% and $55 \pm 1$ at\% $\mathrm{Al}$

for the single pulse $\left(\phi_{\mathrm{avg}}=3.7 \mathrm{~J} / \mathrm{cm}^{2}\right)$ and 100-pulse $\left(\phi_{\mathrm{avg}}=1.7 \mathrm{~J} / \mathrm{cm}^{2}\right)$ experiments, indicating that segregation increases with more pulses in the high-fluence regime.

The chemical composition of the nanoparticles that were ejected from the surface and impacted 
the TEM grid during twenty-five, one hundred-pulse experiments at a fluence of $1.7 \mathrm{~J} / \mathrm{cm}^{2}$ (see red square in Figure 1) was measured via EDS in both the TEM and SEM. A typical TEM bright field image of the particles is shown in Figure 5. It is apparent that two populations of particles were present - those nanoparticles having a diameter approximately 100-200 nm and nanoclusters of particles with diameters in the range of 1-30 $\mathrm{nm}$. The nanoclusters settled onto the grid in large agglomerates while the larger nanoparticles tended to be isolated. Fifty-three SEM EDS and fifteen TEM EDS measurements gave a composition $42 \pm 15$ at\% $\mathrm{Al}$ for the large particles and $56 \pm 12$ at\% $\mathrm{Al}$ for the nanoclusters, where the uncertainty is the standard deviation of all the measurements. No outliers were excluded from the analysis above. In addition, the combined nanoparticle and nanocluster chemical concentrations varied between the TEM grid spaces analyzed, suggesting an angular dependence to the ablation of $\mathrm{Al}$ and $\mathrm{Ni}$ atoms. Both the nanoparticles and nanoclusters were Al-rich compared to the target in some grid spaces and Al-lean in other grid spaces. However, regardless of the local composition in the grid space, the nanoclusters were always enriched in $\mathrm{Al}$ relative to the larger nanoparticles. Due to the experimental setup, it was not possible to quantify the spatial/angular dependence of the composition as in other studies [20, 32].

Selected area diffraction patterns (SADPs) were acquired on the agglomerates of nanoclusters and nanoparticles to determine the crystallinity and crystal structures. In all cases, both the nanoparticles and nanoclusters were determined to be crystalline. The best fit of the diffraction rings and lattice spacings from the SADPs suggested a combination of $\mathrm{NiAl}, \mathrm{NiO}, \mathrm{Ni}_{3} \mathrm{Al}$, and metallic Al. The patterns were evaluated against all intermetallic compounds in the Ni-Al binary and possible Ni-Al-O oxides, as shown in Table 1.

\section{Discussion}

The experimental results detailed above support three key ideas - that the fs ablation behavior of $\mathrm{NiAl}$ is distinct from both $\mathrm{Ni}$ and $\mathrm{Al}$, that there is size-dependent segregation of $\mathrm{Ni}$ and $\mathrm{Al}$ in the nanoparticles and nanoclusters formed during pulsed laser ablation, and that there is preferential removal of $\mathrm{Al}$ from the laser target during high-fluence pulsed laser ablation. 


\subsection{Ablation thresholds}

The two temperature model was used to fit the data from both experiments to the following dependencies $[14,15]$.

$$
\begin{aligned}
& d_{0}=\delta \ln \frac{\phi_{\mathrm{avg}}}{F_{\mathrm{th}}^{\delta}} \\
& d_{0}=l \ln \frac{\phi_{\mathrm{avg}}}{F_{\mathrm{th}}^{l}}
\end{aligned}
$$

where $d_{0}$ is the maximum ablation depth of the crater, $\delta$ and $l$ are the optical and electronic heat penetration depths in the material relating to the low-fluence and high-fluence ablation regimes, and $F_{\mathrm{th}}$ is the threshold for the respective dependency. The data from the single-pulse experiments were fit using the weighted least squares method and the data in the 100-pulse experiments were fit using a modified weighted least squares method allowing for a transition region between the two regimes that has zero weight. This modification was motivated by results such as in Figure 2 where both high and low-fluence regimes coexist in substantial fractions near the crossover between the two models. The fit to the 100-pulse data determined the transition region to be $0.59-1.26 \mathrm{~J} / \mathrm{cm}^{2}$. The best fit parameters are listed in Table 2 .

As stated in Section 1, the single-pulse ablation thresholds of the pure constituent metals are $105-135 \mathrm{~mJ} / \mathrm{cm}^{2}$ for $\mathrm{Al}[9,28]$ and $40-42 \mathrm{~mJ} / \mathrm{cm}^{2}$ for $\mathrm{Ni}[9,11]$. Interestingly, a simple rule of mixtures argument to estimate an ablation threshold in the range $73-89 \mathrm{~mJ} / \mathrm{cm}^{2}$ can explain the single-pulse ablation threshold of the intermetallic compound, which is $83 \pm 4 \mathrm{~mJ} / \mathrm{cm}^{2}$. This is an unexpected agreement because the bonding of NiAl is stronger and more directional compared to $\mathrm{Ni}$ or $\mathrm{Al}$, giving the intermetallic a much higher melting point than either of the constituents [33]. This result suggests that the fs ablation threshold is not directly linked to atomic stability in a material. Further, as discussed in Section 4.3, this result complicates the understanding of preferential ablation in the high-fluence regime.

The differences between the fitting parameters $\delta$ and $l$ for the single pulse and 100-pulse tests are not significant whereas the differences in the thresholds, $F_{\text {th }}^{\delta}$ and $F_{\text {th }}^{l}$, are significant. This incubation effect has been studied previously [10,34]. In both cases the threshold is lower for the 100-pulse experiment, which leads to a lower value of $\phi_{2}^{*}$, the fluence at which high-fluence regime dominates. Following Mannion et al [10], one can solve for the incubation coefficient $S$ in

$$
F_{\mathrm{th}}(N)=F_{\mathrm{th}}(1) N^{S-1}
$$


where $N$ is the number of pulses incident on the sample and $F_{\text {th }}$ is the ablation threshold. This gives $S=0.95 \pm 0.01$ and $S=0.84 \pm 0.02$ for the low-fluence and high-fluence regimes where the error results from propagation of the uncertainties in Table 2. These values are in good agreement with incubation coefficients reported for other metals $(S=0.83-0.92)[10,34]$.

\subsection{Size-dependent segregation of nanoparticles}

As shown in Figure 4, nanoclusters remaining on the surface after a 100-pulse exposure are enriched in $\mathrm{Al}$ compared to the surrounding irradiated surface. While it is unlikely that the EDS technique is accurately measuring the true concentration of the particles, there is little doubt of the trend. The TEM and SEM analysis of the size-dependent segregation of particles ejected from the surface during a 100-pulse high-fluence or 1000-pulse low-fluence experiment has demonstrated that the nanoclusters tend to be rich in $\mathrm{Al}$ compared to the bulk composition while the larger nanoparticles tend to be Al-lean. The diffraction patterns of the nanoclusters were consistent with a combination of $\mathrm{FCC} \mathrm{Al}, \mathrm{Ni}_{3} \mathrm{Al}$, and $\mathrm{NiAl}$. $\mathrm{NiO}$ did not improve the fit of the diffraction rings, but is likely present based on the presence of oxygen in the EDS signal.

To the authors' knowledge, this is the first observation of size-dependent chemical segregation in nanoparticle formation from fs laser ablation. This observation is in stark contrast to the analysis of other nanoparticle compounds such as $\mathrm{PtPb}$ nanoparticles formed via low-fluence fs pulsed laser ablation in methanol wherein the nanoparticles (measured via EDS, SAD, XRD) "reserved the composition of the bulk target," although it was noted that particles smaller than $30 \mathrm{~nm}$ were amorphous while those larger were crystalline [1].

There are a few possible explanations for this observation:

(i) $\mathrm{Ni}$, which has a higher melting and boiling point than $\mathrm{Al}$, may nucleate from the cooling liquid-like or plasma phase first and grow into larger Ni-rich nanoparticles. The $\mathrm{Al}$ atoms have more time to coalesce into Al-rich vapor agglomerates from the Al-rich vapor/plasma plume because they cool to a lower temperature before condensing. They then re-solidify into clusters of small nanoparticles that are Al-rich without much time for particle growth.

(ii) $\mathrm{Al}$ atoms will vaporize from both the hot target and ablated particles after the laser pulse because $\mathrm{Al}$ has a higher vapor pressure and lower boiling point than Ni. This leaves the surface and larger nanoparticles Al-depleted and provides a source for Al-rich nanocluster growth before settling on the TEM grid or inside the laser crater. 
(iii) There is plasma phase segregation of the $\mathrm{Ni}$ and $\mathrm{Al}$ atoms due to relative masses. The ions and atoms ejected from the surface collide with air molecules and the more massive Ni atoms/ions are less impeded by these collisions and travel in a narrower path than the $\mathrm{Al}$ atoms/ions. This causes a spatial segregation of $\mathrm{Ni}$ and $\mathrm{Al}$ particles because the $\mathrm{Al}$ particles are scattered to a larger volume. The resulting difference in particle density affects the relative potential for the nucleated particles to grow, meaning that it is expected that the lighter element (which is scattered to a larger degree) would form smaller nanoparticles.

As expanded upon in Section 4.3, the third possibility (mass-based segregation) is the most likely explanation for size-dependent segregation of the nanoparticles.

\subsection{Target surface enrichment}

As in Section 3.3, it was observed during the high-fluence multiple-pulse experiments that the composition of the surface of ablation craters in the target becomes increasingly depleted in Al. To further corroborate this observation, EDS analysis was performed on a 100-pulse very high fluence experiment $\left(\phi_{\mathrm{avg}}=6.4 \mathrm{~J} / \mathrm{cm}^{2}\right)$ and found that the center of the crater had a composition of 40.5 at\% Al that monotonically approached the bulk composition at the edge of the laser crater. In contrast, as stated in Section 3.2, pulsed laser ablation in the low-fluence regime did not cause the target to deviate from the initial composition. There are a few common explanations for the preferential removal of $\mathrm{Al}$ over $\mathrm{Ni}$ atoms from the target in the high-fluence ablation regime:

(i) Al may become depleted from the target due to preferential evaporation from the hot surface of the target in the high-fluence region of the pulse. Al has a significantly higher vapor pressure than $\mathrm{Ni}$ and therefore has more time to evaporate after each laser pulse. Continued laser pulsing of the same spot will result in depletion of $\mathrm{Al}$ from the target and enrichment of $\mathrm{Al}$ in any nanoclusters that condense back on the target surface. Figure 4a corroborates this argument because the enrichment of $\mathrm{Al}$ in the nanoclusters from the single pulse is only $1.4 \%$ greater than stoichiometric versus $5 \%$ from 100 pulses at a lower fluence.

(ii) There is diffusive segregation of $\mathrm{Ni}$ to the surface of the target upon cooling, which causes $\mathrm{Ni}$ enrichment near the surface only.

(iii) The relative ablation rates of $\mathrm{Ni}$ and $\mathrm{Al}$ in the high-fluence regime are not dependent on their individual ablation thresholds $\left(105-135 \mathrm{~mJ} / \mathrm{cm}^{2}\right.$ for $\mathrm{Al}[9,28]$, and $40-42 \mathrm{~mJ} / \mathrm{cm}^{2}$ for $\mathrm{Ni}$ 
$[9,11])$, but rather depend on some other property such as the respective vapor pressures at the temperatures of interest. According to the CRC handbook, $\log \left(\mathrm{VP}_{A l}\right)-\log \left(\mathrm{VP}_{N i}\right)=9.6-4.3$ over the range 500 to $1000 \mathrm{~K}[35]$.

It is relevant that previous low-fluence fs ablation studies in vacuum on the formation of $\mathrm{CoPt}$ (L1 $1_{0}$ structure) thin films observed consistent Co-enrichment in the deposited film and Co-depletion in the laser target (as measured via XRD) and attributed it to the large variation in vapor pressures [2]. Similar vapor pressured-attributed enrichment has also been observed with high-fluence ns pulsed laser deposition of Al-Sn (immiscible system) thin films in vacuum [36]. Further, a study on the low-fluence fs laser ablation in air of TiN found the irradiated zone to be depleted in N, which has a higher vapor pressure than $\mathrm{Ti}[27]$.

However, preferential ablation of one species based on vapor pressure is not always the case. High-fluence ns pulsed laser deposition films of $\mathrm{NbAl}_{3}$ in vacuum were found to be "very nearly stoichiometric" [37, 38] despite an enormous difference in vapor pressure $\left(\log \left(\mathrm{VP}_{A l}\right)-\log \left(\mathrm{VP}_{N b}\right)=\right.$ 40.1-19.5 over 500-1000 K [35]). Further, a study of the fs pulsed laser formation of PtIr nanoparticles in acetone found no deviation from the target composition [39] and a study of the fs pulsed laser formation of $\mathrm{PbPt}$ nanoparticles in methanol also found no deviation from target composition [1]. The difference in vapor pressures of these systems over the same temperature range is 11-5.6 and 36-16 orders of magnitude for PtIr and PbPt [35]. This suggests that vapor pressures are not the only controlling factor for enrichment of alloys and compounds during pulsed laser ablation and deposition.

A fourth possibility to explain the difference in ablation rates for the fs laser experiments is the difference in atomic mass between the elements. Some of the energy absorbed by the target during a laser pulse is converted into kinetic energy. Assuming that each atom inherits the same amount of kinetic energy, lighter elements/ions will obtain a faster velocity and therefore can travel further away from the target on average before condensing back into the solid phase. In the above examples, this simple argument explains the segregation behavior for all of the fs pulsed laser systems. The principal systems showing no preferential ablation during fs pulse laser experiments were $\mathrm{PbPt}$ and PtIr wherein the atomic mass difference of these systems is only about 2 and $6 \%$. In systems exhibiting significant differences in relative atomic mass ( $>50 \%$, e.g. CoPt, NiAl, TiN), the target was always depleted in the lighter element. Moreover, mass-based segregation was observed in fs 
pulsed laser deposition of $\mathrm{BaTiO}_{3}$ [32]. It was found that the lighter element, Ti, preferentially deposited at smaller angles compared to $\mathrm{Ba}$, which segregated to wider angles. However, the authors did not specify whether the target experienced preferential removal of the lighter element. This argument does not explain the segregation in ns laser ablation, but femtosecond and nanosecond ablation experiments are fundamentally disparate because the fs pulse length is much shorter than required for atoms or ions to move. None of the fs laser pulse is absorbed by melted target or the vapor/plasma plume during ablation as it is in ns ablation [30]. Therefore, mass-based chemical enrichment of the surface is the most likely explanation, although more experiments are needed to confirm this.

To address the peak-valley chemical segregation observed in the LIPSS of the one hundred lowfluence pulse experiment, there are two likely explanations for $\mathrm{Al}$ enrichment at the peaks. The first option, there is near-surface diffusion or convective currents causing $\mathrm{Al}$ atoms to move to the peaks while $\mathrm{Ni}$ atoms preferentially move to the valleys. This movement could be due to a combination of dynamic strain, temperature, and pressure gradients involved in the fs laser ablation event. Recent hydrodynamical models based on Marangoni convection suggest that this is a feasible explanation for atomic segregation in the low-fluence regime [40]. Second, it is likely that the characteristic X-rays emitted from the valleys of the LIPSS will pass through the nearby peaks on the way to the EDS detector and so, on average, pass through more attenuating material than the X-rays emitted from the peaks of the structures. The signal from lower energy photons is more significantly shielded than the higher energy photons because mass attenuation coefficients of X-rays are a strong function of energy [41]. Therefore, the low-energy EDS signal from $\mathrm{Al}(\mathrm{K} \alpha=1.48 \mathrm{keV})$ is expected to be attenuated to a greater degree than the high-energy signal from the $\mathrm{Ni}(\mathrm{K} \alpha=7.47$ $\mathrm{keV}$ ) when measured in the valleys of the LIPSS. It is therefore possible that the EDS chemical segregation measurement is not accurate, but rather a figment of the surface geometry. However, the degree of segregation $( \pm 2$ at\% Al) gives credence to the possibility that true surface segregation is occuring between the peaks and valleys of the LIPSS. Further studies of the fs ablation behavior of compounds are required to determine the true mechanism for the apparent chemical segregation.

Figure 6 shows a schematic summarizing the observed fs pulsed laser ablation behavior of NiAl in this study. In the high-fluence regime, the target becomes depleted in Al. Large nanoparticles 
that are Al-depleted impact the TEM grid while groups of Al-rich small nanoclusters settle on the TEM grid and the target laser crater. In the low-fluence regime, the target composition does not change and similar size-dependent segregation is seen as in the high-fluence case. More controlled experiments of fs pulsed laser ablation of compound materials are needed to elucidate the nature and causes of size-dependent segregation and preferential ablation. Further studies of compound ablation behaviors as a function of fluence and ambient environment (vacuum, air, solvent) will be needed to elucidate these observations and determine whether or not atomic mass controls this behavior.

\section{Summary and Conclusions}

i. The single-pulse fs laser ablation threshold of $\mathrm{NiAl}$ was distinct from both $\mathrm{Ni}$ and $\mathrm{Al}$ and was found to be $\phi_{\text {avg }}=83 \pm 4 \mathrm{~mJ} / \mathrm{cm}^{2}$ with the transition to the high-fluence ablation regime at $\phi_{2}^{*}=2.8 \pm 0.3 \mathrm{~J} / \mathrm{cm}^{2}$.

ii. There is chemical segregation and departure from the bulk composition during the formation of the nanoparticles during both the high-fluence and low-fluence ablation regimes.

(a) The material that ejected from the target surface and deposited on a TEM grid as clusters of smaller nanoparticles (nanoclusters) tended to be rich in $\mathrm{Al}$.

(b) The material that ejected from the target surface and deposited on a TEM grid as larger nanoparticles tended to be $\mathrm{Al}$ depleted.

(c) The small nanoparticles that adhere to the surface of the irradiated crater after multi-pulse or single-pulse experiments in the high-fluence regime tend to be rich in $\mathrm{Al}$.

iii. The surface of the target becomes progressively leaner in $\mathrm{Al}$ with high-fluence pulsed laser ablation. The surface of the target does not change composition during low-fluence pulsed laser ablation.

iv. The crystal structure of both larger and smaller nanoparticles was consistent with a combination of $\mathrm{FCC} \mathrm{Al,} \mathrm{NiAl}, \mathrm{Ni}_{3} \mathrm{Al}$, and $\mathrm{NiO}$ at high fluence.

\section{Acknowledgments}

The authors are indebted to VK Tolpygo for intellectual prodding, MP Echlin for enthusiastic participation in discussion, and JA Love for generosity with TEM support grids. This work was 
supported under NSF grant DMR 1105672. The MRL Shared Experimental Facilities are supported by the MRSEC Program of the NSF under Award No. DMR 1121053; a member of the NSF-funded Materials Research Facilities Network (www.mrfn.org). 


\section{References}

[1] K. Hagedorn, B. Liu, A. Marcinkevicius, Intermetallic PtPb nanoparticles prepared by pulsed laser ablation in liquid, Journal of The Electrochemical Society 160 (2) (2013) F106-F110.

[2] T. Trelenberg, L. Dinh, B. Stuart, M. Balooch, Femtosecond pulsed laser ablation of metal alloy and semiconductor targets, Applied Surface Science 229 (1) (2004) 268-274.

[3] Y. Cheng, H.-L. Tsai, K. Sugioka, K. Midorikawa, Fabrication of 3D microoptical lenses in photosensitive glass using femtosecond laser micromachining, Applied Physics A 85 (1) (2006) $11-14$.

[4] R. R. Gattass, E. Mazur, Femtosecond laser micromachining in transparent materials, Nature Photonics 2 (4) (2008) 219-225.

[5] S. Hypsh, Femtosecond laser processing overcomes barriers for use in medical device manufacturing, Advanced Materials \& Processes 172 (11) (2014) 26.

[6] M. P. Echlin, M. Straw, S. Randolph, J. Filevich, T. M. Pollock, The TriBeam system: Femtosecond laser ablation in situ SEM, Materials Characterization.

[7] J. P. McDonald, V. R. Mistry, K. E. Ray, S. M. Yalisove, Femtosecond pulsed laser direct write production of nano- and microfluidic channels, Applied Physics Letters 88 (18) (2006) $183113-183113$.

[8] D. J. Jorgensen, T. M. Pollock, M. R. Begley, Dynamic response of thin films on substrates subjected to femtosecond laser pulses, Acta Materialia 84 (2015) 136-144.

[9] M. K. Kim, T. Takao, Y. Oki, M. Maeda, Thin-layer ablation of metals and silicon by femtosecond laser pulses for application to surface analysis, Japanese Journal of Applied Physics 39 (11R) (2000) 6277.

[10] P. Mannion, J. Magee, E. Coyne, G. O'Connor, T. Glynn, The effect of damage accumulation behaviour on ablation thresholds and damage morphology in ultrafast laser micro-machining of common metals in air, Applied Surface Science 233 (1) (2004) 275-287. 
[11] S. Amoruso, R. Bruzzese, X. Wang, N. Nedialkov, P. Atanasov, Femtosecond laser ablation of nickel in vacuum, Journal of Physics D: Applied Physics 40 (2) (2007) 331.

[12] B. J. Demaske, V. V. Zhakhovsky, N. A. Inogamov, I. I. Oleynik, Ultrashort shock waves in nickel induced by femtosecond laser pulses, Physical Review B 87 (5) (2013) 054109.

[13] C. Cheng, X. Xu, Mechanisms of decomposition of metal during femtosecond laser ablation, Physical Review B 72 (16) (2005) 165415.

[14] K. Furusawa, K. Takahashi, H. Kumagai, K. Midorikawa, M. Obara, Ablation characteristics of $\mathrm{Au}, \mathrm{Ag}$, and $\mathrm{Cu}$ metals using a femtosecond Ti: sapphire laser, Applied Physics A 69 (1) (1999) S359-S366.

[15] S. Nolte, C. Momma, H. Jacobs, A. Tünnermann, B. Chichkov, B. Wellegehausen, H. Welling, Ablation of metals by ultrashort laser pulses, JOSA B 14 (10) (1997) 2716-2722.

[16] S. Baudach, J. Bonse, J. Krüger, W. Kautek, Ultrashort pulse laser ablation of polycarbonate and polymethylmethacrylate, Applied Surface Science 154 (2000) 555-560.

[17] H. Kumagai, K. Midorikawa, K. Toyoda, S. Nakamura, T. Okamoto, M. Obara, Ablation of polymer films by a femtosecond high-peak-power Ti: Sapphire laser at $798 \mathrm{~nm}$, Applied Physics Letters 65 (14) (1994) 1850-1852.

[18] J. Krüger, W. Kautek, Femtosecond-pulse visible laser processing of transparent materials, Applied Surface Science 96 (1996) 430-438.

[19] A. Dragonmir, J. G. McInerney, D. N. Nikogosyan, Femtosecond measurements of two-photon absorption coefficients at $\lambda=264 \mathrm{~nm}$ in glasses, crystals, and liquids, Applied Optics 41 (21) (2002) 4365-4376.

[20] A. Borowiec, M. Mackenzie, G. Weatherly, H. Haugen, Femtosecond laser pulse ablation of GaAs and InP: studies utilizing scanning and transmission electron microscopy, Applied Physics A 77 (3-4) (2003) 411-417.

[21] T. Trelenberg, L. Dinh, C. Saw, B. Stuart, M. Balooch, Femtosecond pulsed laser ablation of GaAs, Applied Surface Science 221 (1) (2004) 364-369. 
[22] S. Besner, J.-Y. Degorce, A. Kabashin, M. Meunier, Influence of ambient medium on femtosecond laser processing of silicon, Applied Surface Science 247 (1) (2005) 163-168.

[23] A. Kumar, T. M. Pollock, Mapping of femtosecond laser-induced collateral damage by electron backscatter diffraction, Journal of Applied Physics 110 (8) (2011) 083114.

[24] N. Semaltianos, W. Perrie, P. French, M. Sharp, G. Dearden, S. Logothetidis, K. Watkins, Femtosecond laser ablation characteristics of nickel-based superalloy C263, Applied Physics A 94 (4) (2009) 999-1009.

[25] W. Kautek, J. Krueger, Femtosecond pulse laser ablation of metallic, semiconducting, ceramic, and biological materials, in: Europto High Power Lasers and Laser Applications V, International Society for Optics and Photonics, 1994, pp. 600-611.

[26] A. A. Oraevsky, L. B. Da Silva, A. M. Rubenchik, M. D. Feit, M. Glinsky, M. D. Perry, B. M. Mammini, W. Small, B. C. Stuart, Plasma mediated ablation of biological tissues with nanosecond-to-femtosecond laser pulses: relative role of linear and nonlinear absorption, Selected Topics in Quantum Electronics, IEEE Journal of 2 (4) (1996) 801-809.

[27] G. Dumitru, V. Romano, H. Weber, M. Sentis, W. Marine, Femtosecond ablation of ultrahard materials, Applied Physics A 74 (6) (2002) 729-739.

[28] S. Amoruso, R. Bruzzese, M. Vitiello, N. Nedialkov, P. Atanasov, Experimental and theoretical investigations of femtosecond laser ablation of aluminum in vacuum, Journal of Applied Physics 98 (4) (2005) 044907.

[29] J. McDonald, D. Das, J. Nees, T. Pollock, S. Yalisove, Approaching non-destructive surface chemical analysis of CMSX-4 superalloy with double-pulsed laser induced breakdown spectroscopy, Spectrochimica Acta Part B: Atomic Spectroscopy 63 (5) (2008) 561-565.

[30] J. Reif, Laser-Surface Interactions for new Materials Production: Tailoring Structure and Properties, Vol. 130 of Springer Series in Materials Science, Springer, 2010, Ch. 2: Basic Physics of Femtosecond Laser Ablation, pp. 19-42.

[31] D. Drouin, A. Couture, D. Joly, X. Tastet, V. Aimez, R. Gauvin, "casino v2.42 - a fast and 
easy-to-use modeling tool for scanning electron microscopy and microanalysis users", Scanning 29 (2007) 92-101.

[32] E. Millon, J. Perrière, R. Defourneau, D. Defourneau, O. Albert, J. Etchepare, Femtosecond pulsed-laser deposition of $\mathrm{BaTiO}_{3}$, Applied Physics A 77 (1) (2003) 73-80.

[33] H. Okamoto, Al-Ni (aluminum-nickel), Journal of Phase Equilibria 14 (2) (1993) 257-259.

[34] Y. Jee, M. F. Becker, R. M. Walser, Laser-induced damage on single-crystal metal surfaces, JOSA B 5 (3) (1988) 648-659.

[35] D. R. Lide (Ed.), CRC handbook of Chemistry and Physics, 84th Edition, CRC Press, Boca Raton, Florida, 2003.

[36] A. Perrone, A. Zocco, H. de Rosa, R. Zimmermann, M. Bersani, Al-Sn thin films deposited by pulsed laser ablation, Materials Science and Engineering: C 22 (2) (2002) 465-468.

[37] H. Chung, M. Jilavi, T. Duffey, M. Shannon, W. Kriven, J. Mazumder, $\mathrm{NbAl}_{3} / \mathrm{Al}$ microlaminated thin films deposited by UV laser ablation, Thin Solid Films 388 (1) (2001) 101-106.

[38] T. Duffey, T. McNeela, T. Yamamoto, J. Mazumder, A. Schawlow, Absorption spectroscopic measurements of plume density and temperature in production of nanocrystalline $\mathrm{NbAl}_{3}$ by laser ablation deposition, Physical Review B 51 (20) (1995) 14652.

[39] J. Jakobi, A. Menéndez-Manjón, V. S. K. Chakravadhanula, L. Kienle, P. Wagener, S. Barcikowski, Stoichiometry of alloy nanoparticles from laser ablation of PtIr in acetone and their electrophoretic deposition on PtIr electrodes, Nanotechnology 22 (14) (2011) 145601.

[40] G. D. Tsibidis, C. Fotakis, E. Stratakis, From ripples to spikes: A hydrodynamical mechanism to interpret femtosecond laser-induced self-assembled structures, Physical Review B.

[41] J. H. Hubbell, S. M. Seltzer, Tables of x-ray mass attenuation coefficients and mass energyabsorption coefficients $1 \mathrm{kev}$ to 20 mev for elements $\mathrm{z}=1$ to 92 and 48 additional substances of dosimetric interest, Tech. rep., National Inst. of Standards and Technology-PL, Gaithersburg, MD (United States). Ionizing Radiation Div. (1995). 
[42] J. R. Taylor, An Introduction to Error Analysis, 2nd Edition, University Science Books, Suasalito, CA, 1997.

\section{Appendices}

\section{A. Powder diffraction simulations}

Selected area diffraction patterns (SADPs) were obtained using two different camera lengths in an FEI T20 TEM. A Au standard was used to calibrate the camera lengths. SADPs were taken both over large regions of the $\mathrm{Cu}$ (Formvar) grid, and over small groupings of nanoparticles. JEMS software was then used to simulate powder diffraction patterns of various phases along the $\mathrm{Ni}-\mathrm{Al}$ binary systems, as well as other oxide phases commonly found in the Ni-Al system. The phase matching criteria was based primarily on d-spacings, but relative intensities were also considered.

SADPs and simulated patterns for the two best matching phases, $\mathrm{NiO}$ and $\beta$-NiAl, are shown in Figure 7. The NiO phase matched the higher intensity experimental diffraction rings very well. These included the (111), (200), (220), (311), (222), and (400) rings, as shown in Figure 7a. The simulated $\beta$-NiAl phase contains a (100) superlattice reflection with relatively low intensity, which matched the corresponding SADP well. In addition, the (111), (200), and (211) rings matched the SADP well with respect to d-spacings., as shown in Figure $7 \mathrm{~b}$.

The experimental SADPs and simulated ring patterns for the partially matched phases, including $\gamma$-(Al) and $\gamma^{\prime}-\left(\mathrm{Ni}_{3} \mathrm{Al}\right)$, are shown in Figure 8. The $\gamma-(\mathrm{Al})$ simulated pattern matched the intensities of the nearby diffraction rings very well, but the lattice spacings are slightly smaller in the simulated pure $\mathrm{Al}$ compared to the experimental SADP, as shown in Figure 8a. The $\gamma^{\prime}-\left(\mathrm{Ni}_{3} \mathrm{Al}\right)$ simulated pattern d-spacings matched the most intense d-spacings from the SADP, but the intensities at each ring were not consistent with the SADP, as shown in Figure 8b. The (110) superlattice reflection matched the d-spacing from a very faint ring in the SADP. 


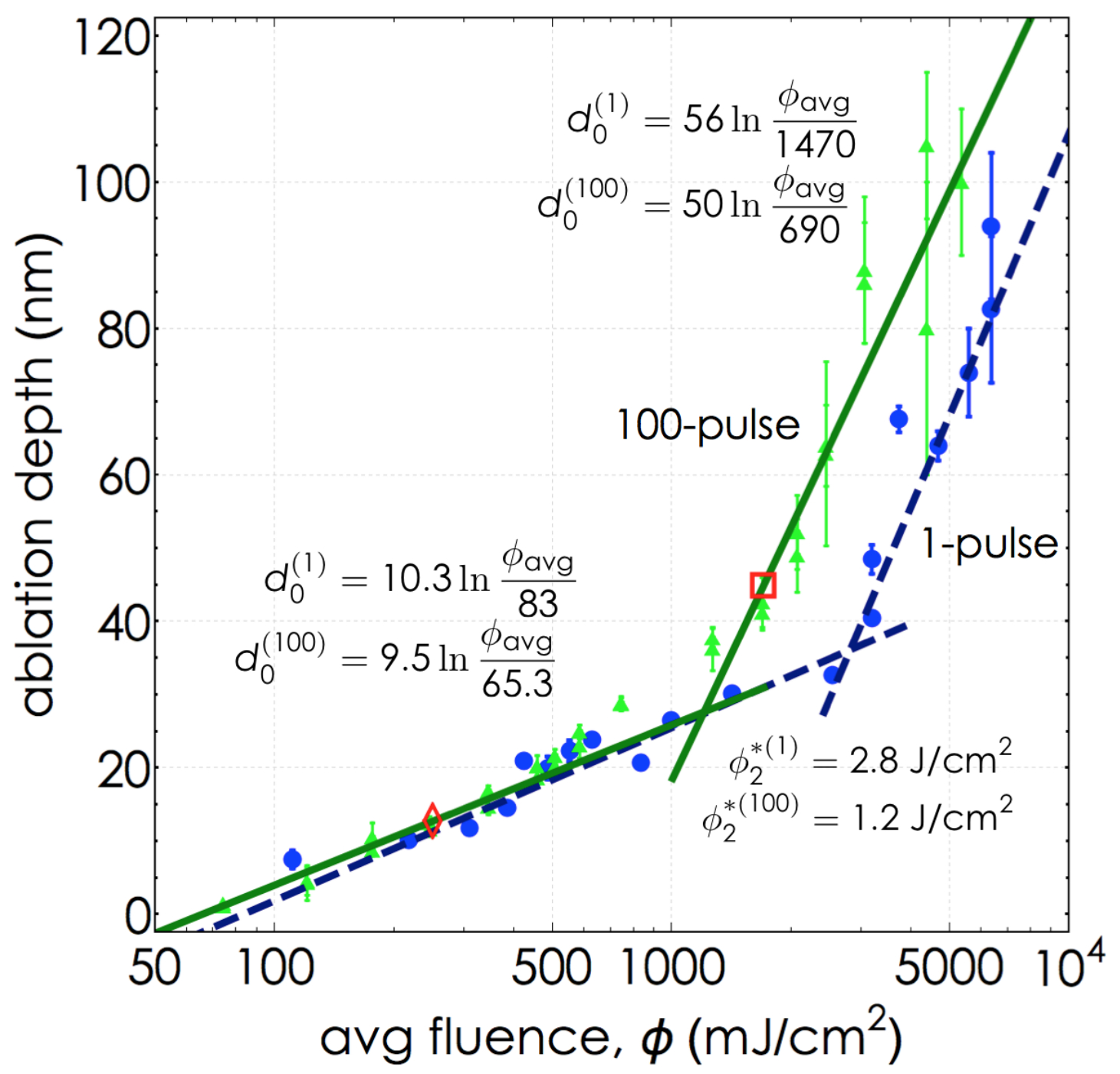

Figure 1: The maximum ablation depth, $d_{0}$, of $\mathrm{NiAl}$ as a function of the laser fluence with 150 fs pulses for single pulses (dashed blue line) and 100-pulses (solid green line). The 100-pulse data are presented as the average ablated depth per pulse. The ablation thresholds are $83 \pm 4$ and $65.3 \pm 0.4 \mathrm{~mJ} / \mathrm{cm}^{2}$ for the single and 100-pulse experiments. The thresholds for the high-fluence ablation regime, defined by the intersection of the low-threshold and high-threshold lines are $2.8 \pm 0.3$ and $1.2 \pm 0.2 \mathrm{~J} / \mathrm{cm}^{2}$ for the single and 100-pulse experiments. The red diamond and square $(\diamond, \square)$ indicate the fluences at which nanoparticles were collected on TEM grids during multi-pulse experiments $(250$ $\mathrm{mJ} / \mathrm{cm}^{2}$ and $\left.1.7 \mathrm{~J} / \mathrm{cm}^{2}\right)$. 


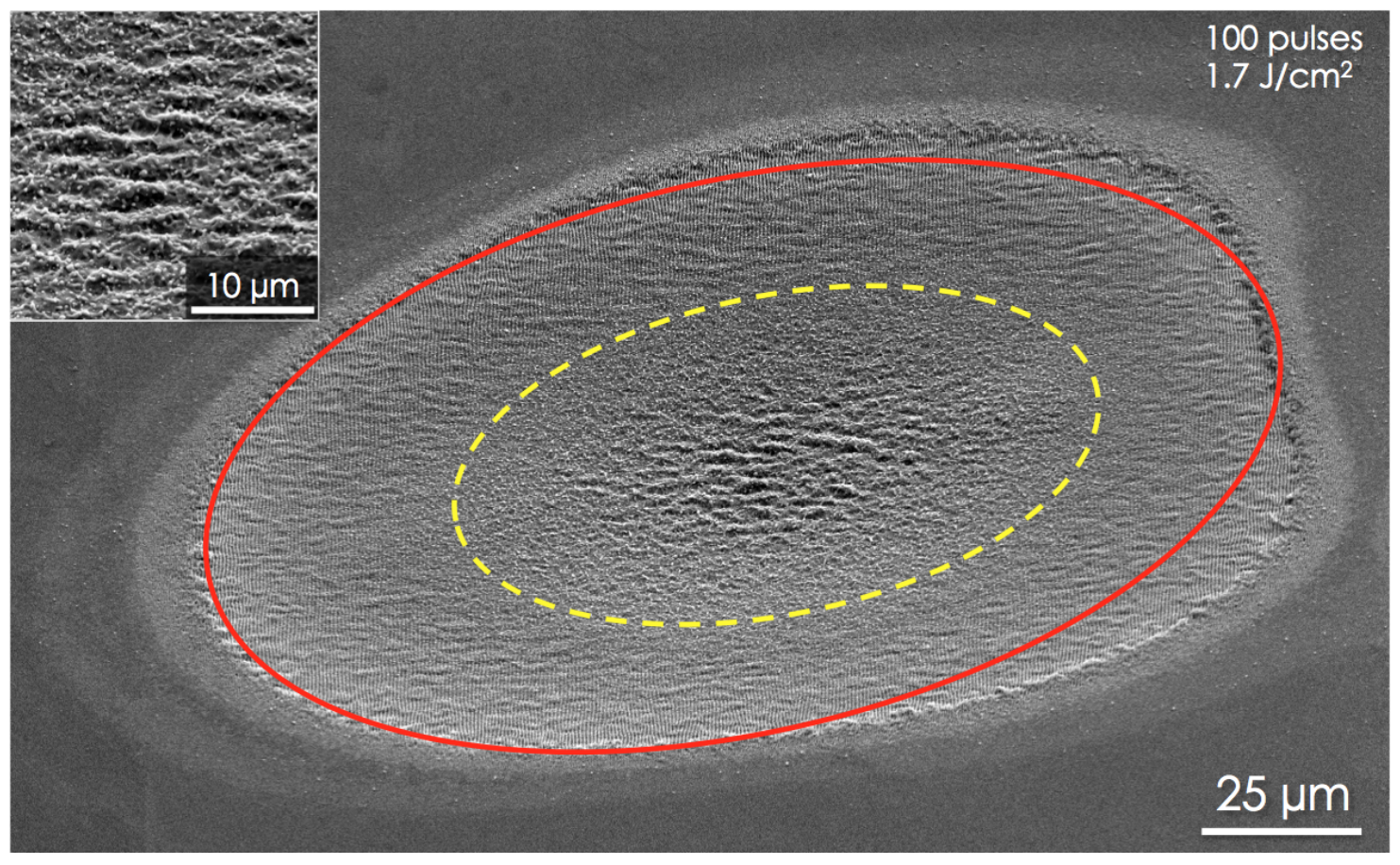

Figure 2: A secondary electron image, $40^{\circ}$ tilted view, of a 100-pulse fs ablation experiment of $\mathrm{NiAl}$ with $\phi_{\mathrm{avg}}=$ $1.7 \mathrm{~J} / \mathrm{cm}^{2}$. This is the same ablation crater shown in Figure $4 \mathrm{~b}$. Inside the solid red line but outside the dashed yellow line, one can see the LIPSS, characteristic of low-fluence ablation, while inside the dashed yellow line the fluence has exceeded the high-fluence threshold as evidenced by the formation of nanoparticles and the presence of a re-solidified layer. The inset shows a magnified view of the center of the pulse crater (at $40^{\circ}$ tilt) where the nanoparticles are more clearly visible. 


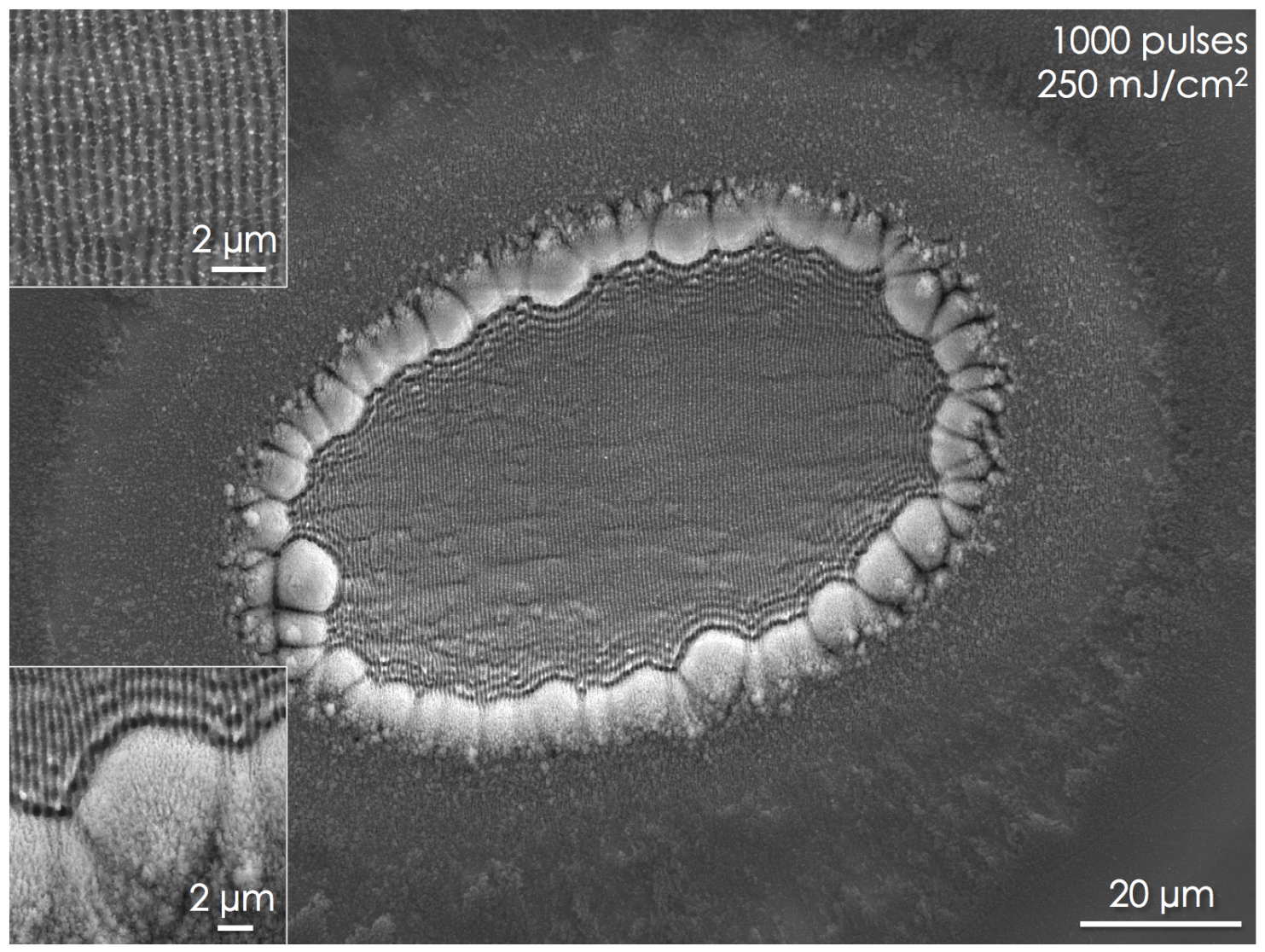

Figure 3: Example of a NiAl ablation crater after one thousand pulses with $\phi_{\text {avg }}=250 \mathrm{~mJ} / \mathrm{cm}^{2}$. The upper inset is a magnified image of the center of the crater and highlights the clearly defined LIPSS. The lower inset shows more detail of the Al-rich redeposition layer on the edge of the crater. 


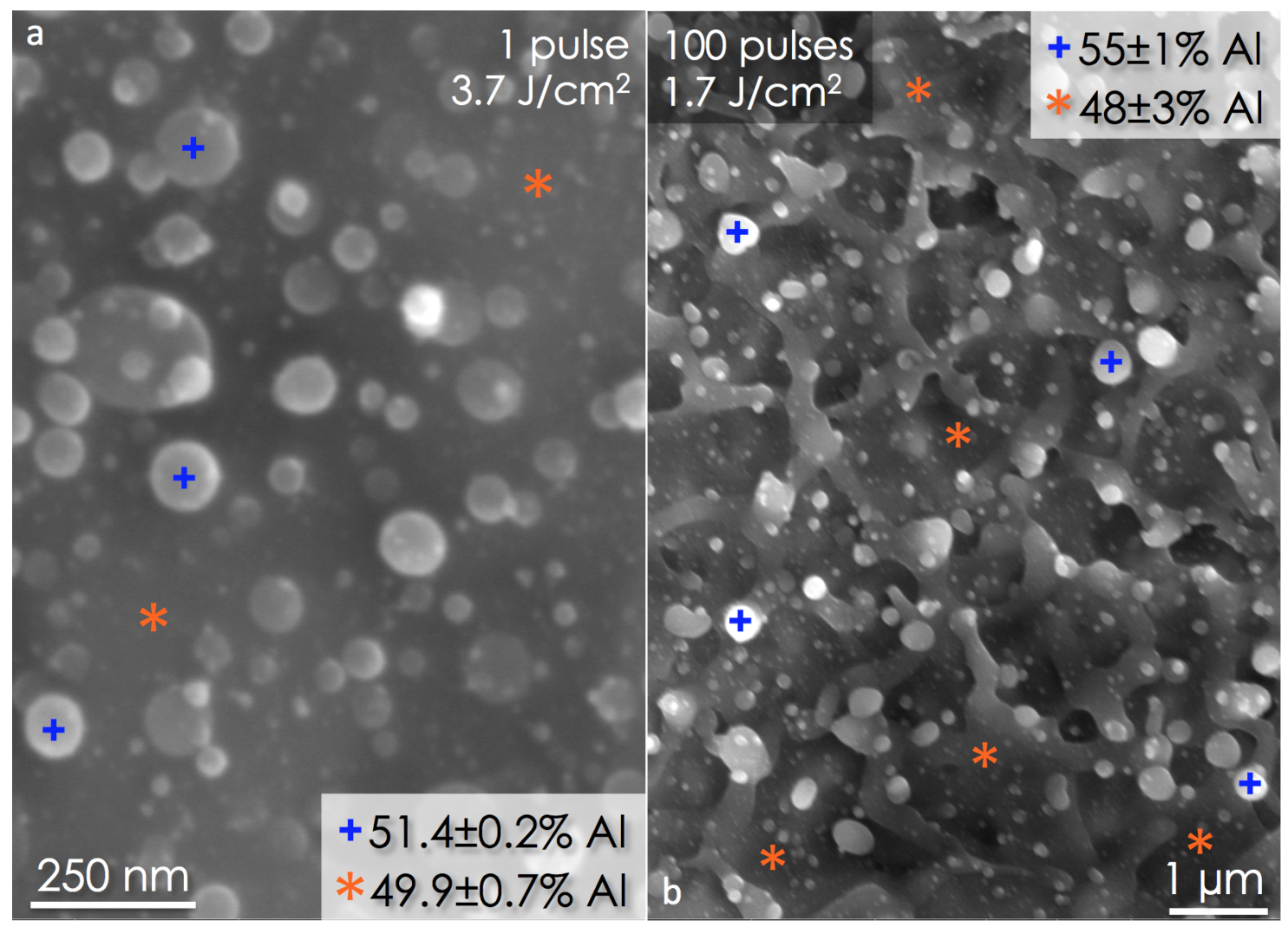

Figure 4: a. Example of the smaller nanoclusters that remained in the NiAl ablation crater after a single pulse with $\phi_{\mathrm{avg}}=3.7 \mathrm{~J} / \mathrm{cm}^{2}$. b. Example of nanoclusters remaining in the ablation crater after 100-pulses with $\phi_{\text {avg }}=$ $1.7 \mathrm{~J} / \mathrm{cm}^{2}$. This close up image is taken in plan view from the crater in Figure 2. The blue crosses (+) indicate points where the EDS measurements for the nanoclusters were taken and the orange asterisks $(*)$ indicate the locations where the background target chemistry was measured. A total of four measurements of each type were taken for (a) and twelve of each type for (b). The uncertainty is the standard deviation between these measurements. 


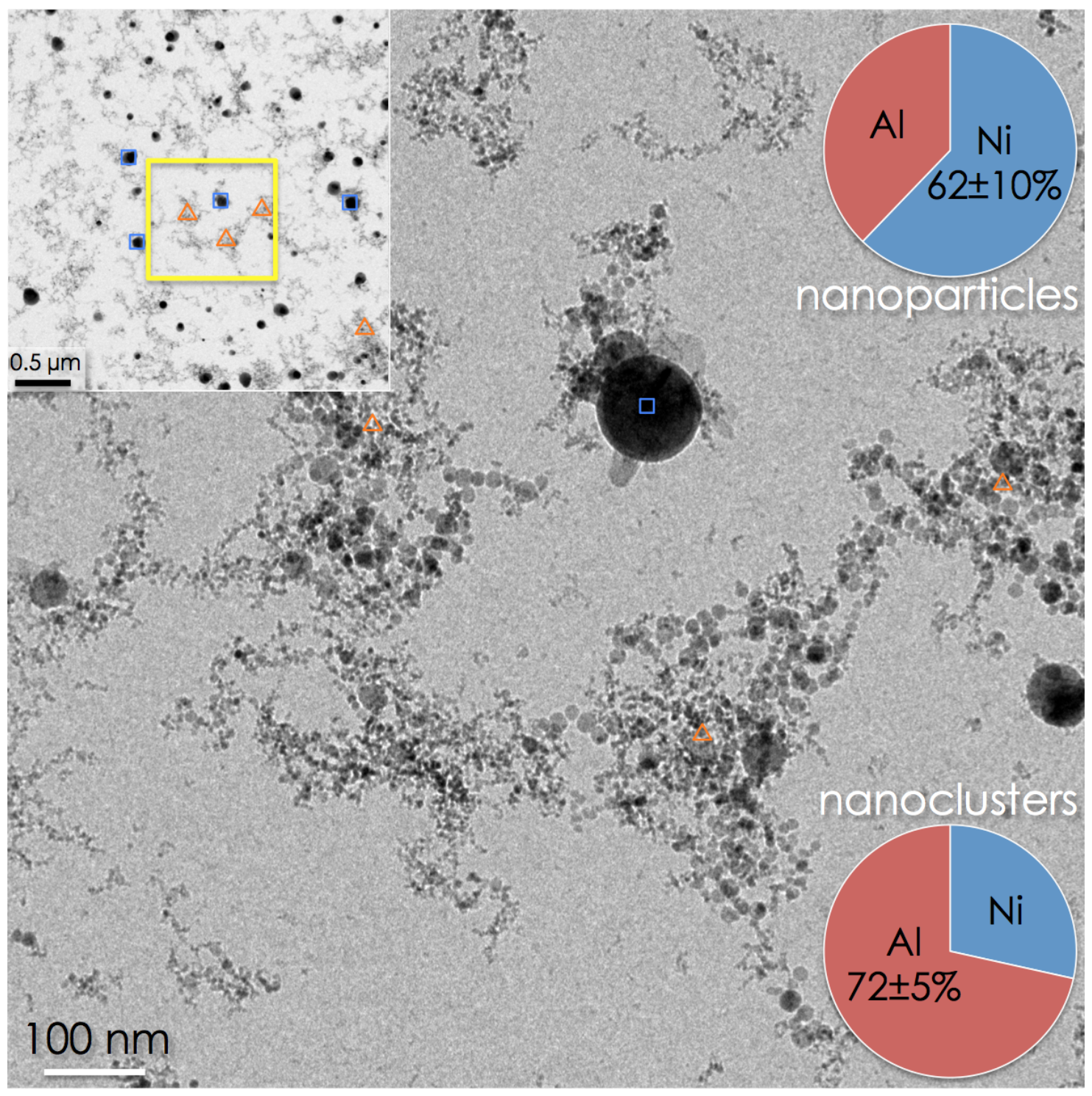

Figure 5: Bright field TEM image showing the bimodal distribution of particles created during a series of 100-pulse ablation experiments on NiAl. The laser fluence was $1.7 \mathrm{~J} / \mathrm{cm}^{2}$, the same as in Figures 2 and $4 \mathrm{~b}$. The average composition and standard deviation of the four measurements of nanoclusters denoted by the orange triangles $(\triangle)$ was found to be $72 \pm 5$ at $\% \mathrm{Al}$. The composition of four of the the larger nanoparticles, denoted by the blue squares ( $\square$ ) was $46 \pm 19$ at\% Al. The large variability in the large particle measurements was likely due to significant overlap and close proximity of the nanoclusters to the large nanoparticles. 


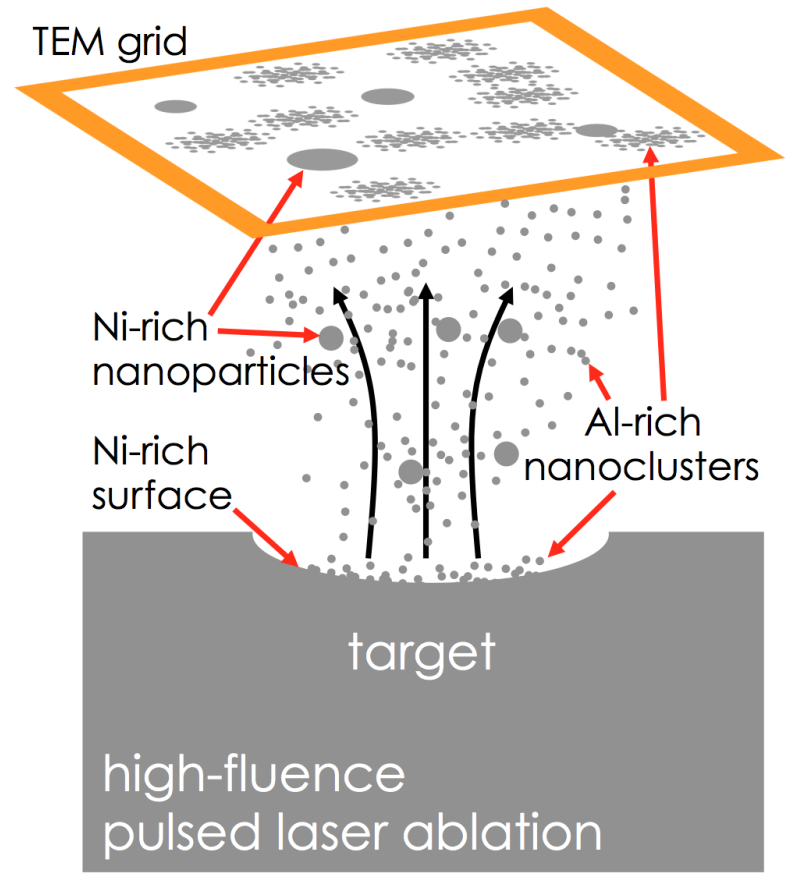

Figure 6: A schematic of the observed ablation behavior for high-fluence fs pulsed laser ablation of NiAl. Following a number of laser pulses the TEM grid positioned parallel to the target has many tightly grouped Al-rich nanoclusters with diameter 1-30 nm. There also exists larger isolated nanoparticles that are Ni-rich. A large number of Al-rich nanoclusters remain on the surface inside the target crater after laser pulsing. 


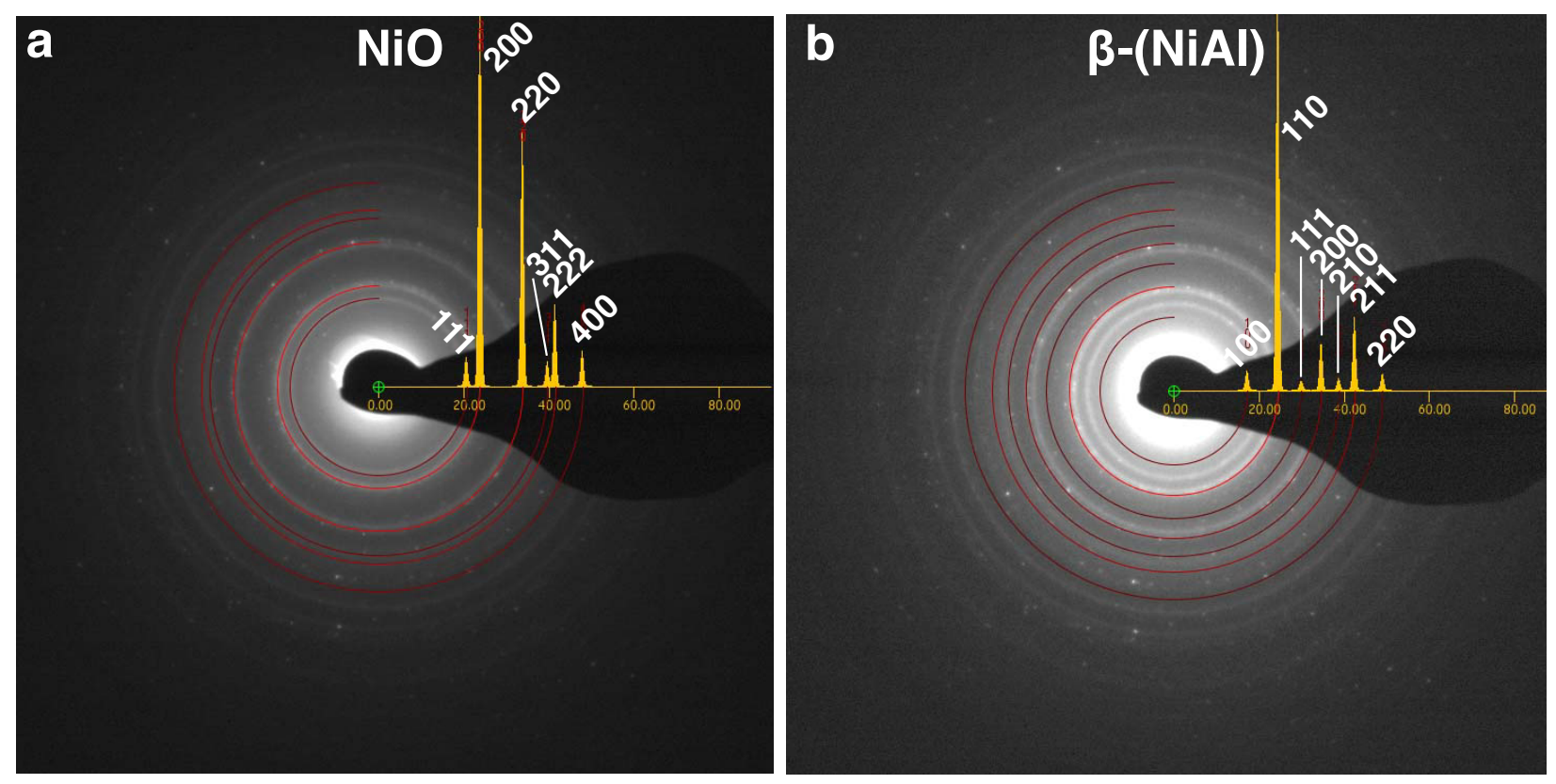

Figure 7: Simulated powder diffraction patterns overlaid on top of the experimental SADP of (a) NiO and (b) $\beta$-NiAl. These two phases matched the experimental SADPs well with respect to d-spacings, and partially agreed with the intensities for each d-spacing. 

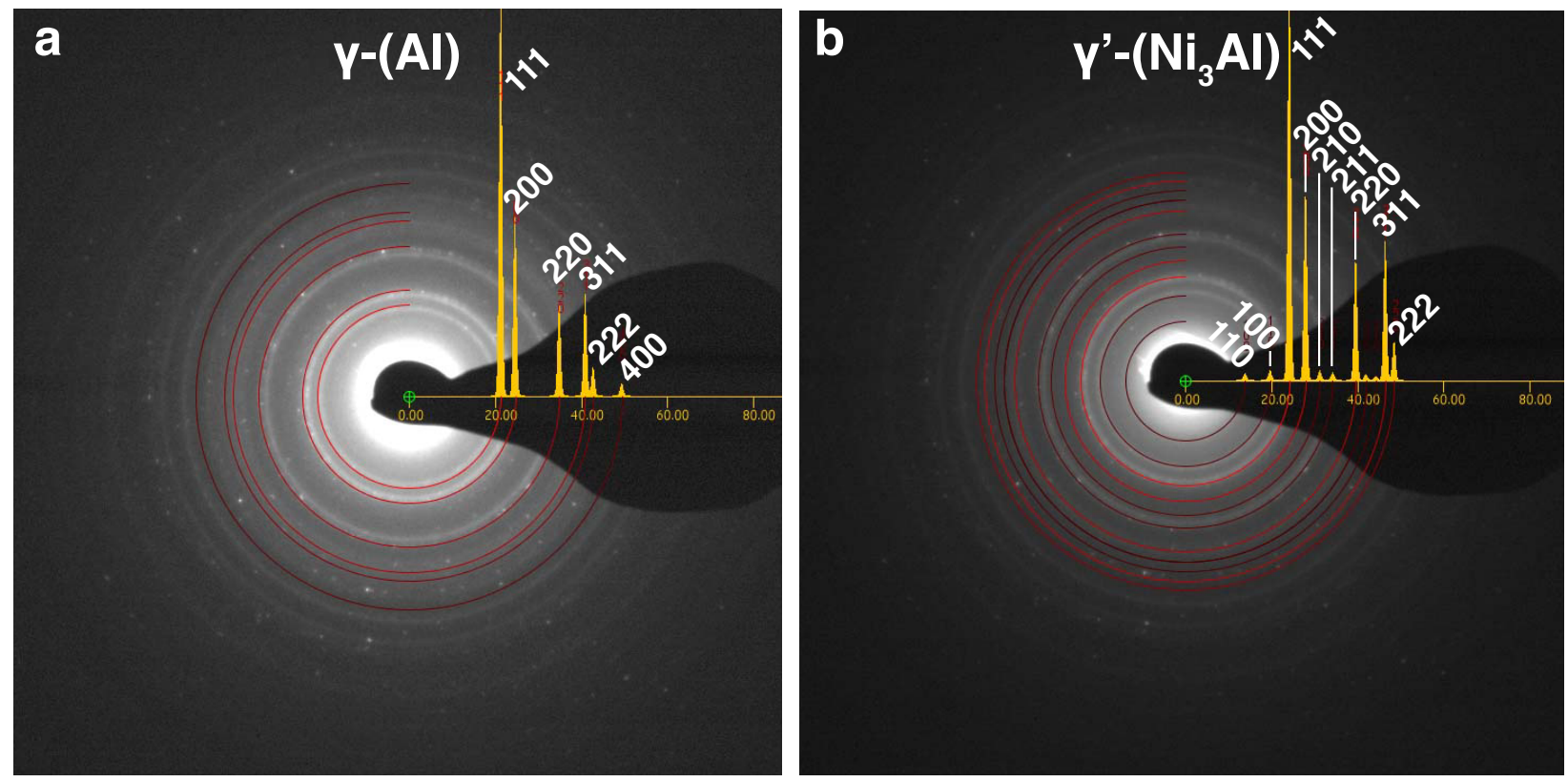

Figure 8: Simulated powder diffraction patterns overlaid on top of the experimental SADP of (a) $\gamma-(\mathrm{Al})$ and (b) $\gamma^{\prime}-\left(\mathrm{Ni}_{3} \mathrm{Al}\right)$. These two phases matched the experimental SADPs well with respect to intensities, and partially agreed with the d-spacings. 
Table 1: Phases and crystal structures investigated using simulated powder diffraction patterns compared to selected area diffraction patterns showing degree of agreement. $\mathrm{Al}$ and $\mathrm{Ni}_{3} \mathrm{Al}$ show partial agreement due to a slight d-spacing discrepancy with the bulk phase. Figures of the measured and simulated diffraction patterns are in the Appendix.

\begin{tabular}{ccccc}
\hline Phase & Prototype & Space Group & Lattice Parameters $(\AA)$ & Match? \\
\hline $\mathrm{Al}$ & $\mathrm{Cu}$ & $\mathrm{Fm} \overline{3} \mathrm{~m}$ & $a=4.049$ & partial \\
$\mathrm{Ni}$ & $\mathrm{Cu}$ & $\mathrm{Fm} \overline{3} \mathrm{~m}$ & $a=3.524$ & no \\
$\mathrm{NiAl}_{3}$ & & $\mathrm{Pnma}$ & $a=6.598, b=7.352, c=4.802$ & no \\
$\mathrm{Ni}_{3} \mathrm{Al}_{5}$ & & $\mathrm{P} \overline{3} \mathrm{ml}$ & $a=4.053, c=4.904$ & no \\
$\mathrm{NiAl}$ & $\mathrm{CsCl}$ & $\mathrm{Pm} \overline{3} \mathrm{~m}$ & $a=2.885$ & yes \\
$\mathrm{Ni}_{3} \mathrm{Al}$ & $\mathrm{AuCu}$ & $\mathrm{Pm} \overline{3} \mathrm{~m}$ & $a=3.572$ & partial \\
$\mathrm{F}_{3} \mathrm{Al}_{2} \mathrm{O}_{3}$ & & $\mathrm{Fd} \overline{3} \mathrm{~m}$ & $a=7.914$ & no \\
$\mathrm{R}-\mathrm{Al}_{2} \mathrm{O}_{3}$ & $\mathrm{Al}_{2} \mathrm{O}_{3}$ & $\mathrm{R} \overline{3} \mathrm{c}$ & $a=4.754, c=12.990$ & no \\
$\mathrm{NiO} \mathrm{NaCl}_{\mathrm{N}}$ & $\mathrm{Fm} \overline{3} \mathrm{~m}$ & $a=4.178$ & yes \\
$\mathrm{NiAl}_{2} \mathrm{O}_{4}$ & & $\mathrm{Fd} \overline{3} \mathrm{~m}$ & $a=8.053$ & no \\
\hline
\end{tabular}


Table 2: Weighted least squares fit [42] parameters for Eqn. 1. The uncertainties arise from the combination of errors in each individual measurement and the confidence of the weighted fit. $\phi_{2}^{*}$ is the intersection between the two dependencies, indicating the value at which the high-fluence ablation behavior dominates the material response.

\begin{tabular}{cccccc}
\hline & $\delta(\mathrm{nm})$ & $F_{\mathrm{th}}^{\delta}\left(\mathrm{mJ} / \mathrm{cm}^{2}\right)$ & $l(\mathrm{~nm})$ & $F_{\mathrm{th}}^{l}\left(\mathrm{~mJ} / \mathrm{cm}^{2}\right)$ & $\phi_{2}^{*}\left(\mathrm{~J} / \mathrm{cm}^{2}\right)$ \\
\cline { 2 - 6 } 1-pulse & $10.3 \pm 0.3$ & $83 \pm 4$ & $56 \pm 3$ & $1470 \pm 50$ & $2.8 \pm 0.3$ \\
100-pulse & $9.5 \pm 0.3$ & $65.3 \pm 0.4$ & $50 \pm 5$ & $690 \pm 60$ & $1.2 \pm 0.2$ \\
\hline
\end{tabular}

